ScIDice

\section{Prevalence Of Enamel Cracks With Various Etiological Factors Amongst Gender - A Cross Sectional Study}

International Journal of Dentistry and Oral Science (IJDOS) ISSN: $2377-8075$

Research Article

Shree Ranjan Pandey ${ }^{1}$, Dr.Pradeep S ${ }^{2 *}$

${ }^{1}$ Department of Conservative dentistry and Endodontics, Saveetha Dental College, Saveetha Institute of Medical and Technical Sciences, Saveetha University, Chennai - 600 077,Tamil Nadu, India.

${ }^{2}$ Associate Professor, Department of Conservative dentistry and Endodontics, Saveetha Dental College, Saveetha Institute of Medical and Technical Sciences, Saveetha University, Chennai - 600 077, Tamil Nadu, India.

\title{
Abstract
}

Introduction: Enamel fractures are one of the most common finding in the oral cavity, however these are often not considered important while the diagnosis of dental diseases is made. The propagation of enamel fracture to a complete fracture involving the pulp is very frequent finding. The present study focuses on the cross sectional data collection from a set of 50 patients under a university setting.

Aim: Prevalence Of Enamel Cracks With Various Etiological Factors Amongst Gender - A Cross Sectional Study. Materials N Methods: The data obtained regarding the enamel cracks were recorded on excel sheet followed by importing of the data to IBM statistical software SPSS 22.0 for statistical analysis. The study revealed that nearly every patient included in the study had enamel fractures.

Results:The enamel fracture is more prevalent in the younger age group of 20 - 30 yrs in males , compared to females.

Conclusion: The study also revealed that the most common cause of enamel fracture is due to parafunctional habits followed by stress as the next relevant finding.

Keywords: Age And Gender Distribution Enamel Cracks; Enamel Crack ; Enamel Fracture.

\section{Introduction}

Enamel is one of the hardest known tooth structures of the body. Enamel fractures are one of the common findings in the oral cavity. The importance of enamel fracture is that if at an early stage it is detected the progression of a minor crack to a full blown enamel fracture can be interrupted. The Dental tissues respond biologically to stresses and strains imposed during mastication.The stresses on these teeth may lead to the formation of microcracks in the dentine and enamel which can propagate, causing symptoms in vital teeth possibly leading to tooth fracture. Cameron in 1964 first used the term "cracked tooth syndrome" (CTS)[1] to describe this phenomenon, which has been defined as "an incomplete facture of a vital posterior teeth involving the dentine and possibly dental pulp". Discomfort when chewing is the most frequent symptom of a cracked tooth. Patient complains that it hurts when biting on one side of the mouth, especially when chewing hard food. The dentist should be suspicious that the tooth is cracked if no caries or sensitive cementum is found and the tooth structures appear normal in the radiograph. The age group affected of the cracked enamel fractures is most commonly seen in middle age group, as compared to older age group and younger population. Cameron determined that predominantly persons older than 50 years suffer from a cracked tooth syndrome1, whereas Hiatt and Talim6 reported the maximum number of split teeth to be in patients between the ages of 40 and 49 . Previously our team has a rich experience in working on various research projects across multiple disciplines [2-16]. Now the growing trend in this area motivated us to pursue this project.

\section{Materials And Methods}

This was a cross sectional study done in a university setup. The study was approved by the Research Ethics Committee of Saveetha Dental College, Saveetha University. The study involved 50 patients within the Dept of Conservative dentistry and endo-

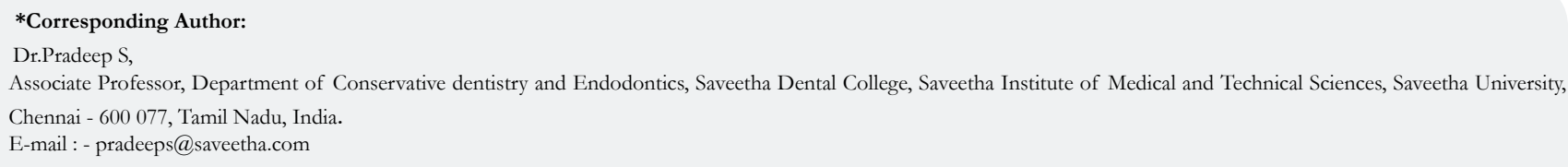

Citation: Shree Ranjan Pandey, Pradeep S.Prevalence Of Enamel Cracks With Various Etiological Factors Amongst Gender - A Cross Sectional Study. Int J Dentistry Oral Sci. 2021;8(7):3274-3278. doi: http://dx.doi.org/10.19070/2377-8075-21000666

Copyright: Pradeep S ${ }^{\odot}$ 2021. This is an open-access article distributed under the terms of the Creative Commons Attribution License, which permits unrestricted use, distribution and reproduction in any medium, provided the original author and source are credited. 
dontics . These cases involved the finding of enamel fractures in these subjects. Other parameters which were recorded apart from enamel fracture were dentinal fracture, attrition, abrasion , erosion , cervical abrasion , cuspal crack, pulpal crack, marginal ridge crack, groove fissure crack, cervical crack, mid tooth buccal crack, restoration crack, vertical root fracture, caries and crack. The etiological factors after studying the literature were narrowed down to causes like biting hard food, accidental biting of hard food , accidental trauma, frequent clenching of jaws, parafunctional forces and stress. Initially the patient history was obtained .The consent was obtained from the pateint to perform the study. Intra oral examination included the use of mouth mirror, explorer, probe. Initally naked eye examination was done which was followed by light curing unit based examination. The data was tabulated in microsoft excel sheet. This data was imported to IBM SPSS statistical software version 22.0. The statistical test used was chi square test.

\section{Results And Discussion}

Associated risk behaviors which can induce cracked tooth are tremendously important in the diagnosis and management of cracked tooth. Patients should be asked whether they have any risk behavior or habit such as tendency to eat hard food, accidental trauma, inappropriate use of teeth and bruxism or clenching. It has been reported that the most common cause for an incomplete fracture is masticatory or accidental trauma. Unintentional biting with physiologic masticatory force on a small and very hard object, such as a seed, may suddenly generate an excessive load due to the very small contact area. As a consequence, the loaded tooth may split or fracture. It has been suggested that one of the steps to identify a crack or fracture is to ask the patient if they remember accidentally biting a hard object and any damaging habit, such as clenching or grinding the teeth, or chewing on ice, pens, hard candy or other objects. Such incidents and habits may correspond to a sudden onset or pain. Interestingly, one article reported a tooth injury in a 28-year-old male patient who liked to chew a soft drink can's ring. Intra-oral examination revealed a chipping of the enamel layer of the buccal cusp, attrition and craze lines on the left first upper premolar where he liked to chew on it. Generalized attrition and vertical craze lines were observed in his whole dentition. Lurie and colleagues also reported the high prevalence of teeth attrition in a group of military aircrews as well as officers on commando units. Dental fracture, enamel chipping and dental attrition are also well prevalent.

The earliest term coined by Gibbs et al in 1954 was called as cuspal fracture odontalgia, followed by fissured fracture by Thoma et al in 1954.The term coined as Cracked tooth syndrome by Cameron in the year 1964, Enamel infarction was given by Andreason in 1981. Hairline fracture was given by the Caulfield in 1981.Craze lines/Tooth structure cracks Abous-Rass in 1983, Cracked cusp syndrome was coined by Kruger in 1984. Tooth infarction was coined by Lost et al in 1989 .

The classification of enamel fractures is as follows

Type 1 - Little or no risk of underlying pathology

a. Craze lines - these are usually linear or vertical and do not widen or become more pronounced as the extend from gingival to occlusal. b. Vertical cracks not associated with restorations and without environmental stain penetration.

\section{c. Cracks that follow natural anatomic grooves.}

d. Cracks with superficial environmental stain penetration

e. Cracks that result from polymerisation shrinkage of composites.

Proposed treatment modalities for type 1 defects include preventive measures such as no treatment, continued observation, occlusal adjustments and protective occlusal splints.

Type 2 - Moderate risk of underlying pathology

a. Wedge shaped enamel ditching resulting from loss of enamel tooth structure with no prior restoration often associated with wear facets and localised occlusal loading centered over an otherwise benign crack.

b. Wedge shaped enamel ditching resulting from loss of enamel tooth structure with an adjoining restoration, often associated with wear facet and localised occlusal loading centered over otherwise benign crack.

c. Cracks that detour from or do not follow the anatomic cracks Proposed treatment modalities for type 2 defects include preventive measures, a review of patient history of thermal and functional sensitivity,restorative investigation, or definitive restorative treatment if the current treatment is deemed compromised.

Type 3 - High risk of underlying pathology

a .Diagonal crack branching off the vertical crack, these are often indicative of late stage oblique incomplete fracture.

b. Horizontal or diagonal cracks that normally emanate from the corner of the restoration, they narrow as they extend gingivally and are typically non linear.

c. Cracks that house the debris with or without previous restoration (indicating a crack size of approximately $200 \mathrm{u}$ or greater).

d. Pairs of cracks that outline an area Cusps or marginal ridges of discoloured enamel, these show a high potential for an underlying dentinal crack and future complete fracture.

e. Cracks with corresponding halo of brown gray or white centred on the crack.

There are several treatment modalities for type 3 enamel fractures, the protocol for high risk enamel fractures calls for removal of old restoration if present. If the decay or microleakage is there , standard treatment is indicated.If underlying cause is dentinal fracture protection from occlusal forces is indicated.How early and in what manner teeth with microscopic dentinal cracks should be treated with depends upon the clinicians assessment.

The American Association of Endodontists (AAE) has identified five types of cracks in teeth.6 Whereas it is important as a clini- 
cian to be familiar with all crack forms as an aide in diagnosis, it is often difficult to distinguish clinically among the various types of cracks. The first fracture and the most benign is a craze line. Craze lines are visible fractures that only involve enamel. However, it is not always possible to determine that a visible fracture is limited to enamel. Fractured cusps originate in the crown of the tooth, extend into dentin, and the fracture terminates in the cervical region. They are usually associated with large restorations causing unsupported cuspal enamel. A cracked tooth is defined by the AAE as a crack extending from the occlusal surface of the tooth apically without separation of the two segments. A split tooth is a crack that extends through both marginal ridges usually in a mesiodistal direction, splitting the tooth completely into two separate segments. Vertical root fractures originate in the root, and are generally complete, although they may be incomplete. A problem common to all the classification systems is that they fail to connect the descriptions to the clinical consequences or treatment recommendations[17].

The results obtained were as follows

The most eminent causative factors as the causative agent for enamel fractures were found to be parafunctional habits, stress followed by unilateral chewing.

The etiological agent labelled as "eating hard food" had a count of 6 cases, the etiological agent labelled as "accidental biting of hard object" had a count of 4 cases, the etiological agent labelled as "Accidental trauma" had a count of 3 cases, Dark green colour represents the etiological agent labelled as "Thermal induced stress" with a count of 6 cases, Grey colour represents the etiological agent labelled as "parafunctional habits" with a count of 13 cases, Orange colour represents the etiological agent labelled as "unilateral chewing" with a count of 7 cases, Light colour represents the etiological agent labelled as "stress" with a count of 9 cases, Dark blue colour represents the etiological agent labelled as "frequent clenching of teeth" with a count of 2 cases.[Graph 1]

Graph depicting selectively the etiological factors for the cause of enamel fracture.

Light brown coloured bar depicts the causative factor as "acci- dental trauma" with a total percentage of $2.74 \%$ including only 2 cases of enamel fractures.Light blue coloured bar depicts the causative factor as "accidental biting of hard food" with a total percentage of $9.59 \%$ including only 7 cases. Green coloured bar depicts the causative factor as "eating hard food" with a total percentage of $27.40 \%$ including 20 cases of enamel fractures.[Graph 2]

The study involved gender wise distribution of the enamel fractures. Under the section of males maximum enamel fractures were reported under the age group of 20 - 30 yrs with a count of 17 $(23.39 \%)$ depicted by blue colour.followed by 12 cases of enamel fractures at a percentage of $16.44 \%$ depicted by purple colour. Followed by 4 cases of enamel fracture in the age group of 30-40 yrs at a percentage of $5.48 \%$. Under the category of females most common age group involved was depicted by light brown colour at $20.55 \%$ with a count of 15 cases. This was followed by the age group of 20-30 yrs , at a percentage of $15.07 \%$ with a count of 11 , followed further by the age group of $3040 \mathrm{yrs}$ with a count of 9 cases at a percentage of $12.33 \%$. The least involved age group was of above 50 yrs depicted by purple colour with a count of 5 enamel fracture cases at a percentage of $6.85 \%$. [Graph 3]

Previously a study done by Freire Maia et al[18] also reported a similar result where out of boys and girls the maximal enamel fractures were seen in boys aged $8-12$ yrs as compared to girls of similar age group.

Most of the fractures were limited till enamel only and did not propagate to dentine, this result was conclusive with the study done by Tapias MA et al [19].

The maximum number of enamel cracks and fractures were seen in cases of upper anteriors followed by lower anteriors. This result was conclusive with the result obtained by study done by $\mathrm{Ta}-$ pias MA et al [19].

Other relevant findings included the fact that the enamel fractures are less common in older patients [17].

Trauma from parafunctional forces, excursive interferences, injury of the face or mouth, restorative procedures, and thermal expansion and contraction of restorative materials have all been associ-

Graph 1 - Graphs depicting the various etiological factors considered in the study.

Red colour represents the etiological agent labelled as "eating hard food" with a count of 6 cases , Dark brown colour represents the etiological agent labelled as "accidental biting of hard object" with a count of 4 cases , Light green colour represents the etiological agent labelled as "Accidental trauma" with a count of 3 cases , Dark green colour represents the etiological agent labelled as "Thermal induced stress" with a count of 6 cases , Grey colour represents the etiological agent labelled as "parafunctional habits" with a count of 13 cases , Orange colour represents the etiological agent labelled as "unilateral chewing" with a count of 7 cases , Light colour represents the etiological agent labelled as "stress" with a count of 9 cases , Dark blue colour represents the etiological agent labelled as "frequent clenching of teeth" with a count of 2 cases

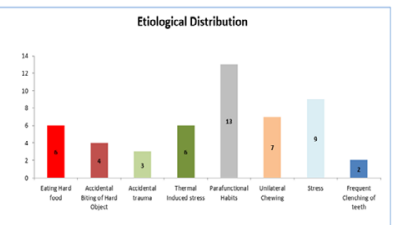


Graph 2 - Graph depicting selectively the etiological factors for the cause of enamel fracture.

Light brown coloured bar depicts the causative factor as "accidental trauma" with a total percentage of $2.74 \%$ including only 2 cases of enamel fractures.

Light blue coloured bar depicts the causative factor as “accidental biting of hard food" with a total percentage of $9.59 \%$ including only 7 cases.

Green coloured bar depicts the causative factor as "eating hard food" with a total percentage of $27.40 \%$ including 20 cases of enamel fractures.

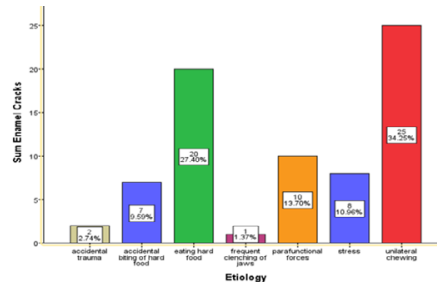

Graph 3 - gender wise distribution of the enamel fractures involved in study.

Under the section of males maximum enamel fractures were reported under the age group of 20 - 30 yrs with a count of $17(23.39 \%)$ depicted by blue colour followed by 12 cases of enamel fractures at a percentage of $16.44 \%$ depicted by purple colour. Followed by 4 cases of enamel fracture in the age group of 30-40 yrs at a percentage of $5.48 \%$. Under the category of females most common age group involved was depicted by light brown colour at $20.55 \%$ with a count of 15 cases. This was followed by the age group of $20-30$ yrs , at a percentage of $15.07 \%$ with a count of 11 , followed further by the age group of 3040 yrs with a count of 9 cases at a percentage of $12.33 \%$.The least involved age group was of above 50 yrs depicted by purple colour with a count of 5 enamel fracture cases at a percentage of $6.85 \%$.

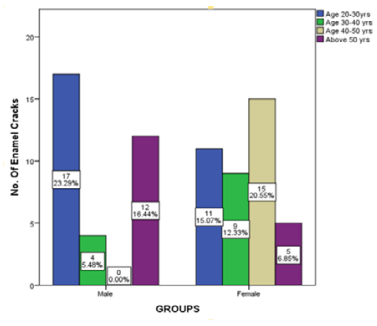

ated with coronal fractures.Combinations of variables such as interferences coupled with a restoration also increase the chance of a crack being present. Clinical observation suggests that fractured cusps and fractured teeth occur more frequently among bruxers than nonbruxers.[17]. This result was conclusive with the current study as the patients with the parafunctional habits like bruxism had more enamel fractures as compared to those without it.

There is no current evidence demonstrating which treatment option has the greatest success rate both from a restorative perspective and from a pulpal health standpoint.So further studies are required in this direction to halt the progression of the enamel fractures at an early stage.

Our institution is passionate about high quality evidence based research and has excelled in various fields[20-30].

\section{Conclusion}

Major causes of enamel and dentinal fracture were accidental trauma , accidental biting of hard object, eating hard food, frequent clenching of jaws, parafunctional habits, stress and unilateral chewing. In the present study it was revealed that maximum involvement of upper anterior teeth was seen followed by lower anterior teeth and lower posterior teeth.

\section{Acknowledgement}

We would like to acknowledge department of conservative and endodontics saveetha dental college for their constant support.

\section{References}

[1]. Gill T, Pollard AJ, Baker J, Tredwin C. Cracked Tooth Syndrome: Assessment, Prognosis and Predictable Management Strategies. Eur J Prosthodont Restor Dent. 2021 Mar 24. Pubmed PMID: 33770422.

[2]. Govindaraju L, Gurunathan D. Effectiveness of Chewable Tooth Brush in Children-A Prospective Clinical Study. J Clin Diagn Res. 2017 Mar;11(3):ZC31-ZC34. Pubmed PMID: 28511505.

[3]. Christabel A, Anantanarayanan P, Subash P, Soh CL, Ramanathan M, Muth usekhar MR, et al. Comparison of pterygomaxillary dysjunction with tuberosity separation in isolated Le Fort I osteotomies: a prospective, multi-centre, triple-blind, randomized controlled trial. Int J Oral Maxillofac Surg. 2016 Feb;45(2):180-5. Pubmed PMID: 26338075.

[4]. Soh CL, Narayanan V. Quality of life assessment in patients with dentofacial deformity undergoing orthognathic surgery--a systematic review. Int J Oral Maxillofac Surg. 2013 Aug;42(8):974-80. Pubmed PMID: 23702370.

[5]. Mehta M, Deeksha, Tewari D, Gupta G, Awasthi R, Singh H, et al. Oligonucleotide therapy: An emerging focus area for drug delivery in chronic inflammatory respiratory diseases. Chem Biol Interact. 2019 Aug 1;308:206215. Pubmed PMID: 31136735.

[6]. Ezhilarasan D, Apoorva VS, Ashok Vardhan N. Syzygium cumini extract induced reactive oxygen species-mediated apoptosis in human oral squamous carcinoma cells. J Oral Pathol Med. 2019 Feb;48(2):115-121. Pubmed PMID: 30451321

[7]. Campeau PM, Kasperaviciute D, Lu JT, Burrage LC, Kim C, Hori M, et al. The genetic basis of DOORS syndrome: an exome-sequencing study. Lancet Neurol. 2014 Jan;13(1):44-58. Pubmed PMID: 24291220.

[8]. Kumar S, Sneha S. Knowledge and awareness regarding antibiotic prophylaxis for infective endocarditis among undergraduate dental students. Asian Journal of Pharmaceutical and Clinical Research. 2016;154.

[9]. Christabel SL, Gurunathan D. Prevalence of type of frenal attachment and morphology of frenum in children, Chennai, Tamil Nadu. World J Dent. 2015 Oct;6(4):203-7. 
[10]. Kumar S, Rahman RE. Knowledge, awareness, and practices regarding biomedical waste management among undergraduate dental students. Asian Journal of Pharmaceutical and Clinical Research. 2017;10(8):341

[11]. Sridharan G, Ramani P, Patankar S. Serum metabolomics in oral leukoplakia and oral squamous cell carcinoma. J Cancer Res Ther. 2017 JulSep;13(3):556-561. Pubmed PMID: 28862226.

[12]. Ramesh A, Varghese SS, Doraiswamy JN, Malaiappan S. Herbs as an antioxidant arsenal for periodontal diseases. J Intercult Ethnopharmacol. 2016 Jan 27;5(1):92-6. Pubmed PMID: 27069730.

[13]. Thamaraiselvan M, Elavarasu S, Thangakumaran S, Gadagi JS, Arthie T. Comparative clinical evaluation of coronally advanced flap with or without platelet rich fibrin membrane in the treatment of isolated gingival recession. J Indian Soc Periodontol. 2015 Jan-Feb;19(1):66-71. Pubmed PMID: 25810596.

[14]. Thangaraj SV, Shyamsundar V, Krishnamurthy A, Ramani P, Ganesan K, Muthuswami M, et al. Molecular Portrait of Oral Tongue Squamous Cell Carcinoma Shown by Integrative Meta-Analysis of Expression Profiles with Validations. PLoS One. 2016 Jun 9;11(6):e0156582. Pubmed PMID: 27280700 .

[15]. Ponnulakshmi R, Shyamaladevi B, Vijayalakshmi P, Selvaraj J. In silico and in vivo analysis to identify the antidiabetic activity of beta sitosterol in adipose tissue of high fat diet and sucrose induced type- 2 diabetic experimental rats. Toxicol Mech Methods. 2019 May;29(4):276-290. Pubmed PMID: 30461321.

[16]. Ramakrishnan M, Bhurki M. Fluoride, Fluoridated Toothpaste Efficacy And Its Safety In Children-Review. International Journal of Pharmaceutical Research. 2018 Oct 1;10(04):109-14.

[17]. Lubisich EB, Hilton TJ, Ferracane J; Northwest Precedent. Cracked teeth: a review of the literature. J Esthet Restor Dent. 2010 Jun;22(3):158-67. Pubmed PMID: 20590967.

[18]. Freire-Maia FB, Auad SM, Abreu MHNG, Sardenberg F, Martins MT, Paiva SM, et al. Prevalence of and factors associated with enamel fracture and other traumas in Brazilian children 8-10 years old. Braz Oral Res. 2018 Aug 13;32:e89. Pubmed PMID: 30110087.

[19]. Tapias MA, Jiménez-García R, Lamas F, Gil AA. Prevalence of traumatic crown fractures to permanent incisors in a childhood population: Móstoles, Spain. Dent Traumatol. 2003 Jun;19(3):119-22. Pubmed PMID: 12752531.

[20]. Vijayashree Priyadharsini J. In silico validation of the non-antibiotic drugs acetaminophen and ibuprofen as antibacterial agents against red complex pathogens. J Periodontol. 2019 Dec;90(12):1441-1448. Pubmed PMID:
31257588.

[21]. J PC, Marimuthu T, C K, Devadoss P, Kumar SM. Prevalence and measurement of anterior loop of the mandibular canal using CBCT: A cross sectional study. Clin Implant Dent Relat Res. 2018 Aug;20(4):531-534. Pubmed PMID: 29624863

[22]. Ramesh A, Varghese S, Jayakumar ND, Malaiappan S. Comparative estimation of sulfiredoxin levels between chronic periodontitis and healthy patients - A case-control study. J Periodontol. 2018 Oct;89(10):1241-1248. Pubmed PMID: 30044495

[23]. Ramadurai N, Gurunathan D, Samuel AV, Subramanian E, Rodrigues SJL. Effectiveness of $2 \%$ Articaine as an anesthetic agent in children: randomized controlled trial. Clin Oral Investig. 2019 Sep;23(9):3543-3550. Pubmed PMID: 30552590

[24]. Sridharan G, Ramani P, Patankar S, Vijayaraghavan R. Evaluation of salivary metabolomics in oral leukoplakia and oral squamous cell carcinoma. J Oral Pathol Med. 2019 Apr;48(4):299-306. Pubmed PMID: 30714209.

[25]. Ezhilarasan D, Apoorva VS, Ashok Vardhan N. Syzygium cumini extract induced reactive oxygen species-mediated apoptosis in human oral squamous carcinoma cells. J Oral Pathol Med. 2019 Feb;48(2):115-121. Pubmed PMID: 30451321.

[26]. Mathew MG, Samuel SR, Soni AJ, Roopa KB. Evaluation of adhesion of Streptococcus mutans, plaque accumulation on zirconia and stainless steel crowns, and surrounding gingival inflammation in primary molars: randomized controlled trial. Clin Oral Investig. 2020 Sep;24(9):3275-3280. Pubmed PMID: 31955271.

[27]. Samuel SR. Can 5-year-olds sensibly self-report the impact of developmental enamel defects on their quality of life? Int J Paediatr Dent. 2021 Mar;31(2):285-286. Pubmed PMID: 32416620.

[28]. R H, Ramani P, Ramanathan A, R JM, S G, Ramasubramanian A, et al. CYP2 C9 polymorphism among patients with oral squamous cell carcinoma and its role in altering the metabolism of benzo[a]pyrene. Oral Surg Oral Med Oral Pathol Oral Radiol. 2020 Sep;130(3):306-312. Pubmed PMID: 32773350.

[29]. Chandrasekar R, Chandrasekhar S, Sundari KKS, Ravi P. Development and validation of a formula for objective assessment of cervical vertebral bone age. Prog Orthod. 2020 Oct 12;21(1):38. Pubmed PMID: 33043408.

[30]. Vijayashree Priyadharsini J, Smiline Girija AS, Paramasivam A. In silico analysis of virulence genes in an emerging dental pathogen A. baumannii and related species. Arch Oral Biol. 2018 Oct;94:93-98. Pubmed PMID: 30015217. 